\title{
RECURSOS HÍDRICOS NA REGIÃO DAS BAIXADAS LITORÂNEAS DO RIO DE JANEIRO: UMA PROPOSTA DE EDUCAÇÃO AMBIENTAL PARA ALUNOS DO SEGUNDO SEGMENTO DO ENSINO FUNDAMENTAL DE ESCOLAS DE CABO FRIO E SILVA JARDIM, RJ
}

\author{
Maria Catarina S. Azevedo ${ }^{1}$ \\ Ronaldo de Souza Veiga ${ }^{2}$
}

\section{RESUMO}

O presente trabalho é resultante de uma proposta apresentada às Secretarias de Educação dos municípios de Cabo Frio e Silva Jardim e busca desenvolver um projeto de educação ambiental em escolas a partir do reconhecimento das características da hidrografia da região das Baixadas Litorâneas do RJ. A referidas redes de ensino foram selecionadas devido às especificidades ambientais destes municípios. Silva Jardim concentra seu território integralmente inserido na Bacia do Rio São João, a segunda maior reserva de água doce do Estado do Rio de Janeiro e que abastece oito municípios litorâneos. Cabo Frio apresenta características opostas à Silva Jardim em relação aos recursos hídricos. Além de possuir escassez de água, a área urbana, onde estão concentrados mais de $75 \%$ de sua população (Censo 2000 - IBGE) registra excessivo aumento do consumo nos meses de verão devido ao intenso fluxo turístico. Diante das especificidades destas cidades, o Projeto propõe às respectivas Redes de Ensino a realização de uma série de atividades, de forma interdisciplinar, em duas escolas de cada município, podendo ser ampliado posteriormente de acordo com os resultados alcançados. Os referenciais teóricos têm como base as diretrizes curriculares nacionais sobre o tema, além de autores que preconizam a bacia hidrográfica como unidade territorial em estudos ambientais. O público alvo é formado por professores e alunos do Segundo Segmento do Ensino Fundamental.

Palavras chave: Interdisciplinaridade, Recursos hídricos, Diversidade ambiental.

\begin{abstract}
The present work is the result of a proposal submitted to the Education Departments of municipalities of Cabo Frio and Silva Jardim and seeks to develop the education/environmental awareness in local schools from the recognition of the characteristics of the hydrography of the region of Coastal Lowlands of RJ. The choice of these networks of teaching are guided by its environmental specificities. Silva Jardim has its territory fully inserted in the basin of São João river and stands out in the conservation of water sources, chiefly the Reservoir of Juturnaíba, the second reserve of fresh water in the State of Rio de Janeiro and that supplies eight coastal municipalities, including Cabo Frio. This city has opposite characteristics to Silva Garden in relation to water resources.In addition to having water scarcity, the urban area, where it is concentrated more than $75 \%$ of its population (Census 2000 - IBGE) records excessive increase in consumption in the summer months due

\footnotetext{
${ }^{1}$ Mestranda em Geografia - UFF Campus Campos dos Goytacazes. E-mail: catarinageo@gmail.com

${ }^{2}$ Mestrando em Geografia - UFF Campus Campos dos Goytacazes. E-mail: vipveiga@ hotmail.com
} 
to the intense tourist flow. Before the specific features of these cities, the Project proposes to these education networks to carry out a series of activities in an interdisciplinary way, in two schools of each municipality, and may be extended later according with the results achieved.The theoretical framework is based on the national curricular guidelines on the subject, in addition to authors who advocate the basin as territorial unit in environmental studies. The target audience is comprised of teachers and students in the Second Segment of the Elementary School.

Keywords: Interdisciplinarity, Water resources, Environmental diversity.

\section{INTRODUÇÃO}

O presente trabalho tem como objetivo desenvolver atividades que possam contribuir para a conscientização da importância da água na atualidade a partir do reconhecimento da região das Baixadas Litorâneas. O público alvo é formado por professores e alunos de escolas das redes municipais de Silva Jardim e Cabo Frio. A escolha dos dois municípios tem como base suas especificidades no contexto regional, em relação aos recursos hídricos. Silva Jardim está inserido integralmente na bacia do Rio São João e destaca-se em relação à conservação dos recursos hídricos. Cabo Frio é a cidade com a maior população da região, com importante atividade turística, caracterizando-se como o principal consumidor desta região hidrográfica.

O município de Silva Jardim é conhecido como "Cidade Verde" devido aos seus aspectos ambientais e possui expressivas áreas de Mata Atlântica. Cerca de 95\% de seu território faz parte da Área de Proteção Ambiental (APA) da Bacia do Rio São João. O município possui ainda o maior número de Reservas Particulares de Patrimônio Natural (RPPNs) do País e concentra outras importantes Unidades de Conservação, como a Reserva Biológica de Poço das Antas e parte do Parque Estadual dos Três Picos. Possui ainda a represa de Juturnaíba, o segundo maior reservatório de água doce do Estado do Rio de Janeiro, responsável pelo abastecimento dos seguintes municípios: Silva Jardim, Saquarema, Araruama, Iguaba Grande, São Pedro da Aldeia, Cabo Frio, Arraial do Cabo, Armação dos Búzios. A população total da área abastecida é de 607.659 habitantes (Estimativa 2014/IBGE) e frequentemente passa de dois milhões de pessoas na alta temporada de verão (dezembro a março), segundo estimativas das Prefeituras e Secretaria Estadual de Turismo. Outro aspecto relevante de Silva Jardim é a relativa proximidade da Região Metropolitana, o que torna o município estratégico no contexto fluminense como importante reserva hídrica não só na atualidade, mas para as próximas décadas. Diante das características ambientais, a educação tem um papel importante de conscientização e formação das novas gerações.

Enquanto Silva Jardim destaca-se devido à alta disponibilidade de água doce, Cabo Frio possui características opostas, com escassez do recurso e alto consumo. Sua população residente, de 204.486 habitantes (Estimativa 2014/IBGE), frequentemente passa de um milhão de pessoas em datas especiais, como réveillon e carnaval. A crise no abastecimento de água provocou problemas no desenvolvimento do turismo no passado. Na década de 1990, o sistema público de água foi privatizado e sucessivamente ampliado visando minimizar os problemas existentes. As Concessionárias responsáveis pelo abastecimento são as empresas Águas de Juturnaíba e Prolagos. Ambas fazem captação de água no reservatório de 
Juturnaíba, localizado em Silva Jardim, realizam o tratamento e distribuição para as oito cidades litorâneas. Entretanto, o crescimento populacional intenso da região das Baixadas Litorâneas agrava a crise de abastecimento, sobretudo no verão com o intenso fluxo de turistas nas cidades litorâneas. A região registrou ainda nas últimas décadas um intenso crescimento populacional. Sua população passou de 389.522 habitantes em 1991 para 810.666 em 2010 (Censos - IBGE). Diante dessas especificidades, a questão hídrica nas Baixadas Litorâneas necessita de planejamento adequado e mostra a importância da educação nesse contexto.

A escolha dos referidos municípios para elaboração deste projeto, apresentado às Secretarias de Educação dos municípios de Silva Jardim e Cabo Frio, teve origem no período de atuação enquanto docente nas respectivas redes de ensino e de pesquisas anteriores sobre o tema. Constatou-se significativo desconhecimento das características socioambientais regionais não só pelos alunos, como também por grande parte dos docentes. Diante destas observações, várias atividades foram realizadas no referido período. Entretanto, a crise hídrica recente, amplamente divulgada pelos meios de comunicação, mostrou a necessidade de retomar as atividades sob uma nova perspectiva. O Projeto está organizado em atividades interdisciplinares e busca o envolvimento de gestores, docentes e alunos com o objetivo de conscientizar sobre a importância daconservação dos recursos hídricos na atualidade e fortalecer o sentimento de pertencimento ao espaço vivido pelas novas gerações.

Entre as referencias teóricas, destacam-se trabalhos que preconizam a importância da bacia hidrográfica como unidade territorial em estudos e pesquisas (CUNHA, 1996) e ainda outros aspectos relevantes relacionados à educação ambiental e a pedagogia dos projetos. Em relação às bacias hidrográficas, observa-se a sua importância como unidade territorial mais indicada nos estudos de recursos hídricos, tanto no planejamento como na gestão das águas. A Lei Federal n. 9.433/97 instituiu a Política Nacional de Recursos Hídricos (PNRH) e enfatiza a importância das bacias hidrográficas.

A Educação Ambiental foi incluída no sistema normativo brasileiro, através da Lei 6.938/81 que trata da Política Nacional do Meio Ambiente e, em seguida, na Constituição Federal/88 (Artigo 225, § 1, VI), cabendo ao poder público a responsabilidade de promover a educação ambiental em todos os níveis de ensino, assim como na conscientização da coletividade para a participação ativa na tutela ambiental. Contudo, mesmo estando previsto na Constituição Federal (CF88) os princípios da educação ambiental, sua regulamentação se efetiva após onze anos, através da Lei 9.795, de 1999, conhecida como "Política Nacional de Educação Ambiental", seguida pelo Decreto 4.281, de 2002.

A Educação Ambiental adquiriu relevância a partir da promulgação da Lei 9.795/99 que institui a Política Nacional de Educação Ambiental (PNEA) e dá outras providências. Segundo esta Lei, Educação Ambiental pode ser definida da seguinte maneira:

"Entendem-se por Educação Ambiental os processos por meio dos quais o individuo e a coletividade constroem valores sociais, conhecimentos, habilidades, atitudes e competências voltadas para a 
conservação do meio ambiente, bem de uso comum do povo, essencial à sadia qualidade de vida e sua sustentabilidade."

Segundo o ProNEA, a Educação Ambiental deve estar em todos os níveis e modalidades de ensino, sendo um direito de todos e deverá ser uma prática educativa permanente. Outro aspecto relevante é o incentivo a participação popular na tomada de decisões, aspecto também destacado pela Lei Federal $n^{\circ}$. 9.433/97, que instituiu a Política Nacional de Recursos Hídricos.

Neste sentido, a educação ambiental é de vital importância, sendo reconhecida pela Lei 9.795/99 como necessária e permanente enquanto processo formal e informal de educação, devendo estar presente em todos os níveis e modalidades educativas (MEC, 2009). A Educação Ambiental deve buscar valores que conduzam a uma convivência harmoniosa com o ambiente e as demais espécies que habitam o planeta, auxiliando o aluno a analisar criticamente o princípio antropocêntrico, que tem levado à destruição inconsequente dos recursos naturais e de várias espécies.

O tema sociedade e meio ambiente sugere maior aproximação, pois, ao tratar da formação socioespacial, das novas territorialidades e temporalidades do mundo atual, abordam-se de forma ampla os processos que geram um determinado Uso e Ocupação da Terra (FAO, 1976), as demandas por recursos naturais, o crescimento populacional e a urbanização, dentre outros. Para Porto Gonçalves (2006 p. 309) essas políticas conhecidas como de ajuste estrutural vêm, de diferentes maneiras, trazendo sérios danos ao meio ambiente e particularmente a perda de diversidade biológica com o incentivo à expansão da agricultura de exportação. Portanto, há evidentes possibilidades de a Geografia integrar-se ao campo interdisciplinar de estudos acerca do meio ambiente.

A busca incessante pela geração e comercialização de riquezas tem levado a humanidade a uma grande crise ambiental. Segundo Vitte (2008, p. 349) "As catástrofes e vulnerabilidades são produzidas pela sociedade à medida que ela própria se realiza na Terra. As catástrofes e os riscos, tão pesquisados e estudados em geografia, concernem à produção humana". Embora o desenvolvimento tecnológico tenha proporcionado avanços na sociedade, ao mesmo tempo este tem alavancado problemas e riscos ambientais que comprometem a qualidade de vida das gerações atuais e futuras. Para David Harvey (2009 p. 281) há muito tempo somos poderosos agentes evolutivos que atuam por meio de todas as coisas, da produção de plantas e animais, da ampla modificação do habitat e do rápido crescimento populacional à difusão e à combinação de espécies em escala global. A preocupação com a proteção do meio ambiente vem aumentando paulatinamente nos últimos 30 anos, tanto que grande parte dos países inclui a tutela ambiental em suas Constituições e cria e/ou (re) estrutura legislações específicas na tentativa de alcançar um desenvolvimento sustentável para as nações.

Diante desse contexto, a Constituição brasileira de 1988 se configura como uma das mais evoluídas no tangente a questão ambiental, pois prevê, além de outras medidas direcionadas para a garantia de um equilibro ambiental, a realização de uma massiva 
educação ambiental em todos os níveis de ensino e a conscientização pública para a preservação do meio ambiente (Constituição Federal, Art. 225).

Segundo Gadotti (2008), a Educação Ambiental é um plano estratégico que envolve escolas, ONGs, empresas e sociedade com o objetivo de introduzir o tema da sustentabilidade nos sistemas educativos e reformar o currículo a partir da cultura sustentável. Gadotti ainda considera que o tema da sustentabilidade é bem maior que a Educação Ambiental, porque envolve também a área econômica da sociedade. Segundo o autor, no momento em que tomamos consciência de que somos cidadãos do mundo e de que o sentido da nossa vida está fortemente relacionado ao planeta, é necessário rever o nosso estilo de vida, até então poluidor e consumista. A preservação do meio ambiente depende de uma consciência ecológica e a formação de consciência depende da educação (GADOTTI, 2008, p. 36).

A degradação do meio ambiente ocorre em toda a parte, com maior ou menor intensidade, dependendo das técnicas utilizadas na exploração dos recursos naturais e da preocupação local com a conservação desses recursos. Para Porto-Gonçalves (2006, p. 288) o fundamento da relação da sociedade com a natureza sob o capitalismo está baseado na separação, a mais radical possível, entre os homens e mulheres, de um lado, e a natureza, de outro.

Isso tem gerado uma série de danos, não só ao meio ambiente natural, como aos seres humanos. A degradação é um dos aspectos inerentes ao processo de construção do espaço urbano, dessa forma, o estudo da problemática ambiental das cidades deve considerar as questões sociais (embates, conflitos, apropriações) que se configuram na formação desse espaço, em especial o que se refere à lógica da sua produção, uma vez que o ambiental não se restringe apenas ao natural.

Na verdade, o desenvolvimento da ciência e da técnica é, sempre, desenvolvimento do conhecimento humano acerca da natureza, inclusive da natureza dos humanos e, assim, esse desenvolvimento sempre intensifica e aprofunda a relação com a natureza (PORTO GONÇALVES, 2006, p. 290) O grande desafio da educação ambiental rumo a um desenvolvimento democrático e sustentável é, paralelamente, a tomada de medidas efetivas que garantam a conservação e proteção ambiental, proporcionando uma educação crítica e inovadora nas camadas formais e informais da sociedade, visando o desenvolvimento sustentável.

Segundo o MEC, a escola pública, em todos os níveis e modalidades da Educação Básica (Educação Infantil, Ensino Fundamental e Ensino Médio), tem como função social formar o cidadão, isto é, construir conhecimentos, atitudes e valores que tornem o estudante solidário, crítico, ético e participativo das decisões da sociedade. Comportamentos ambientalmente corretos devem ser aprendidos na prática, no cotidiano da vida escolar, visando uma compreensão mais ampliada do meio ambiente.

A Educação Ambiental é um processo participativo, onde educandos e educadores assumem interativamente função central no processo de ensino/aprendizagem pretendido, participando ativamente da discussão sobre os problemas ambientais e na busca das soluções para os mesmos. 
A partir de 1996 os Novos Parâmetros Curriculares do MEC incluíram a Educação Ambiental como tema transversal do currículo escolar das escolas públicas. A Educação Ambiental tornou-se lei em 27 de Abril de 1999 (Lei ${ }^{\circ}$ 9.795) e em seu artigo $2^{\circ}$ afirma que: “a educação ambiental é um componente essencial e permanente da educação nacional, devendo estar presente, de forma articulada, em todos os níveis e modalidades do processo educativo, em caráter formal e não formal”.

Segundo os Parâmetros Curriculares (1998, p. 46) a compreensão das questões ambientais pressupõe um trabalho interdisciplinar. A análise de problemas ambientais envolve questões políticas, históricas, econômicas, ecológicas, geográficas, enfim, envolve processos variados, portanto, não seria possível compreendê-los e explicá-los pelo olhar de uma única ciência. Como o objetivo dos estudos da Geografia refere-se às interações entre a sociedade e a natureza, um grande leque da temática ambiental está necessariamente dentro do seu campo de investigação.

Em alguns países desenvolvidos a exemplo do Japão a necessidade de aproximar o ensino da realidade é tão característica que todas as escolas são obrigadas, por lei, a realizar no mínimo um trabalho de campo por semana - um estudo do meio, uma excursão etc. Portanto, é de plena importância à discussão das questões ambientais no processo de aprendizagem dos alunos das Escolas de Cabo Frio e Silva Jardim no Estado do Rio de Janeiro, tendo a educação ambiental como um papel fundamental na tomada de consciência da corresponsabilidade da coletividade na proteção ambiental e, consequentemente, contribui para a democratização das decisões ambientais.

Para Piaget (1970 apud PROFICE e PINHEIRO, 2009) a epistemologia genética estabelece uma continuidade entre o pensamento infantil e o científico, partindo da ideia de que a cognição se desenvolve como um sistema epigenético que proporciona a adaptação do organismo ao ambiente e a adaptação da inteligência ao curso de sua própria estruturação por meio dos processos de assimilação e acomodação. Por conseguinte conhecendo um objeto, o sujeito deve agir sobre ele, transformando a si próprio e ao objeto.

Segundo Profice (2009) na ação o sujeito e o objeto se fundem e o conhecimento surge a partir dessa interação indiferenciada tão característica do pensamento infantil. Progressivamente, essas ações se transformam em operações e se tornam ações interiorizadas. Nessas condições a pesquisa procura estabelecer até que ponto esse indivíduo consegue perceber o ambiente e conceber ou agregar valor, entendendo que a cultura é o próprio processo de evolução no contexto do construtivismo sócio histórico que para Vigotyski (1939 apud PROFICE, 2009) “... inserindo-se no seu ambiente, a criança começa logo a se transformar e a mudar. Isto acontece muito cedo porque a situação cultural já pronta cria nela determinadas formas de adaptação que á muito foram criadas pelos adultos que a rodeiam". 


\section{PROPOSTA DE DESENVOLVIMENTO DO PROJETO}

O presente trabalho tem como objetivo principal propor um projeto interdisciplinar para as Secretarias de Educação dos municípios de Silva Jardim e Cabo Frio. Para o seu desenvolvimento, serão realizadas as seguintes etapas: Criação de um blog e uma página na rede social Facebook para a divulgação de cada etapa do projeto. Serão selecionadas duas escolas da área urbana de cada rede de ensino, com características aproximadas em relação ao quantitativo de alunos e turmas, empenho das equipes gestoras e envolvimento do corpo docente. As atividades para as escolas selecionadas têm duração prevista de um semestre letivo, podendo ser alterado de acordo com as sugestões apresentadas. A segunda etapa consistirá em uma entrevista com aplicação de questionário para os docentes e gestores com o objetivo de identificar as suas principais dificuldades sobre o tema. A partir das solicitações, serão elaborados e disponibilizados materiais de apoio (textos, vídeos, apostila, mapas, entre outros) para os envolvidos nesta etapa. Na etapa seguinte serão realizadas atividades de campo com os docentes em ambas as cidades, onde além do reconhecimento local serão planejadas oficinas para a troca de experiências. A próxima etapa será a definição dos objetivos do projeto de cada escola de acordo com a contribuição de docentes de diferentes áreas, buscando a interdisciplinaridade. A partir da definição desta etapa, cada escola irá definir suas atividades com os alunos. Serão incentivadas as atividades com a utilização e/ou produção de mapas; pesquisas em sites, jornais e demais publicações; construção de maquetes, entre outros. Após o conhecimento prévio sobre o tema, serão realizadas atividades de campo com os alunos e professores nos seguintes locais: Reservatório de Juturnaíba / Estação de Tratamento de Água da Prolagos em São Vicente (Araruama) / Visita a Reserva Biológica de Poço das Antas (Silva Jardim) / visita a área central das cidades de Araruama, São Pedro da Aldeia e Arraial do Cabo de acordo com os objetivos destacados por cada escola. Em Cabo Frio serão realizadas diferentes atividades, com observações nos seguintes pontos: Morro da Guia, Praia do Forte, Centro e Praia do Peró. Os alunos serão orientados a realizar entrevistas com diferentes atores, sobretudo os ligados a atividade turística. $\mathrm{O}$ levantamento de informações sobre os problemas relacionados ao abastecimento de água deverá ser observado nas diferentes atividades. Durante as atividades, os alunos serão orientados a documentar todas as etapas através de imagens e vídeos com uso dos próprios aparelhos celulares ou câmeras digitais. Após as atividades de campo, as equipes deverão sistematizar as informações e apresentar as suas percepções anteriores e atuais sobre a problemática da água no contexto regional das Baixadas Litorâneas. As escolas deverão apresentar a conclusão dos projetos com a divulgação de seus resultados na forma de material escrito ou audiovisual.

\section{EXPECTATIVAS EM RELAÇÃO AO PROJETO}

Esperam-se, ao final deste projeto, os seguintes resultados: a) contribuir para a realização de atividades que integrem docentes de diferentes áreas do conhecimento de forma interdisciplinar de acordo com os princípios preconizados nos Parâmetros Curriculares Nacionais (PCNs) em relação ao Meio Ambiente; b) favorecer o desenvolvimento de atividades sobre as questões socioambientais da região das Baixadas Litorâneas pautadas pelo 
uso da bacia hidrográfica como unidade territorial e de gestão ambiental; c) incentivar a pesquisa sobre os problemas ambientais e a busca de possíveis alternativas na escala local; e d) compreender a importância da educação escolar na formação de sujeitos conscientes em relação às questões ambientais em diferentes escalas.

Em relação aos discentes, são esperados os seguintes resultados: i) desenvolver o reconhecimento da área de estudo de forma integrada entre os diferentes agentes atuantes e a importância da conservação dos recursos naturais; ii) despertar a percepção que os impactos causados pela ação humana possuem consequências que afetam diretamente o cotidiano de suas populações; e iii) compreender que a Região das Baixadas Litorâneas apresenta grande diversidade de paisagens e que o seu desenvolvimento econômico necessita de planejamento adequado segundo suas características locais. Desta forma, espera-se que a educação possa contribuir para formação de sujeitos mais comprometidos com a conservação do ambiente.

\section{CONSIDERAÇÕES FINAIS}

$\mathrm{O}$ presente trabalho baseia-se numa proposta a ser apresentada às Secretarias de Educação dos municípios de Cabo Frio e Silva Jardim. Entende-se que o desenvolvimento do projeto necessita do envolvimento dos docentes, o que será incentivado a partir dos encontros de formação. A disponibilidade de materiais adequados às suas necessidades é fundamental para o pleno desenvolvimento da proposta, assim como a integração entre disciplinas do currículo escolar. Compreende-se que a necessidade do envolvimento dos docentes perpassa pelo fracasso de projetos similares, que utilizam materiais e métodos prontos onde os mesmos são inseridos como meros executores. E, no fracasso dos resultados, são apontados como não "capacitados" em suas atividades. Portanto, a etapa inicial norteará as demais atividades buscando o envolvimento da comunidade docente de forma integrada e participativa para o alcance dos objetivos. Portanto, a partir do envolvimento de todos os participantes, a busca por uma educação pública de qualidade será o foco principal, contribuindo na formação de sujeitos conscientes da limitação dos recursos naturais, sobretudo a água e sua função estratégica no século XXI.

\section{BIBLIOGRAFIA}

BRASIL. Secretaria de Educação Fundamental. Parâmetros Curriculares Nacionais: Geografia/Secretaria de Educação Fundamental - Brasília: MEC/SEF, 1998. p. 46.

BIDEGAIN, PAUlO. Lagoa de Araruama - Perfil Ambiental do Maior Ecossistema Lagunar Hipersalino do Mundo. Rio de Janeiro: SEMADS, 2002.

BIDEGAIN, P. e VOLCKER, C. M. - Bacias Hidrográficas dos Rios São João e das Ostras - Águas, Terras e Conservação Ambiental, CILSJ, 2004.

FUNDAÇÃO CEPERJ. Anuário Estatístico do Estado do Rio de Janeiro, 2013. Disponível em < http://www.ceperj.rj.gov.br/ceep/Anuario2013/index.html.> 
GUERRA, A. J. T.; CUNHA, S. B. da, org. Geomorfologia e meio ambiente. Rio de Janeiro: Bertrand Brasil, 1996. 394 p.

GADOTTI, MOACIR. Ecopedagogia e Educação Sustentável. In: Revista de Educação do CEAP. Salvador. 2008. p. 36.

Revista Educar - Consciência Ambiental. Disponível em: < http://www.conscienciacomciencia.com.br/2010/08/06/revista-educar-consciencia-ambientaltenha-um-minhocario-em-casa $>$ Acesso em: 10/10/2008.

HARVEY, D. Espaços de Esperança. 3. ed. São Paulo: Loiola, 2009. Kish, L. (1987). Statistical design for research. Nova York: Wiley.

IBGE. Censo Demográfico 2010. Disponível em http://www.cidades.ibge.gov.br/xtras/perfil.php?lang=\&codmun=330070 $>$ Acesso em $15 / 05 / 2015$.

PORTO - GONÇALVES, C. W. A Globalização da Natureza e a Natureza da Globalização. Rio de Janeiro: Civilização Brasileira, 2006.

PROFICE, C. C.; PINHEIRO, J. Q. Arquivos Brasileiros de Psicologia. Explorar com crianças: reflexões teóricas e metodológicas para os pesquisadores. v. 61, n. 3, 2009. Disponível em: < http://www.psicologia.ufrj.br/abp/> Acesso em: 10/10/2011. 